ISSN = 1980-993X - doi:10.4136/1980-993X
www.ambi-agua.net
E-mail: ambi-agua@agro.unitau.br
Tel.: (12) 3625-4212

\title{
Qualidade físico-química e microbiológica de água mineral e padrões da legislação
}

(http://dx.doi.org/10.4136/ambi-agua.908)

\author{
Helenilza Ferreira Albuquerque Cunha ${ }^{1}$; Débora Cristina Isacksson Lima² \\ Priscila Nazaré de Freitas Brito ${ }^{3}$; Alan Cavalcanti da Cunha ${ }^{4}$; \\ Arialdo Martins da Silveira Junior ${ }^{5}$; Daímio Chaves Brito ${ }^{6}$. \\ Universidade Federal do Amapá_UNIFAP, Macapá-AP, \\ e-mails: helenilzacunha@ unifap.br $^{1}$, debora_isacksson@ hotmail.com $^{2}$, priscila.nfb@ hotmail.com $^{3}$, \\ alancunha@unifap.br ${ }^{4}$, arialdojunior@hotmail.com ${ }^{5}$, daimiobrito@gmail.com ${ }^{6}$
}

\section{RESUMO}

O objetivo deste estudo foi avaliar parâmetros físico-químicos e microbiológicos da água mineral comercializada na cidade de Macapá e verificar sua conformidade com a legislação. Os padrões legais aceitos para potabilidade de água para consumo humano no Brasil são estabelecidos pela Resolução Diretória Colegiada - RDC 274/2005 da Agência Nacional de Vigilância Sanitária (ANVISA) - que regulamenta as águas minerais e a Portaria 518/2004 do Ministério da Saúde, que estabelece a potabilidade para o abastecimento público. As análises mensais foram feitas em amostras de água em garrafões de $20 \mathrm{~L}$ de três marcas diferentes adquiridas em seis locais comerciais. Parâmetros físico-químicos foram comparados com os descritos pela legislação como turbidez, $\mathrm{pH}$, nitrato, ferro, manganês, alumínio e fluoreto, e os microbiológicos como coliformes totais e Escherichia coli. Os resultados indicaram que o pH encontra-se frequentemente abaixo do limite permitido ao abastecimento público. A elevada concentração de alumínio foi considerada grave, com valores significativamente acima dos padrões permitidos em duas marcas. O flúor apresentou concentrações próximas de zero, apesar da legislação sugerir valores entre $1 \mathrm{mg} / \mathrm{L}$ e $2 \mathrm{mg} / \mathrm{L}$. Os parâmetros microbiológicos em todas as marcas apresentaram coliformes totais, mas Escherichia coli foi registrado em apenas uma amostra. A água mineral é consumida por ser considerado um produto seguro em relação a outras fontes, mas este estudo mostra que a água mineral comercializada em Macapá está frequentemente em não conformidade com a legislação. Recomenda-se atenção na fiscalização especialmente em garrafões de $20 \mathrm{~L}$.

Palavras-chave: Água mineral, RDC 274/2005, análises fisico-químicas, coliforme total, saúde pública.

\section{Physicochemical and microbiological quality of mineral water and the legislation standards}

\section{ABSTRACT}

The objective of this study was to evaluate the physicochemical and microbiological mineral water parameters in the city of Macapá and verify their compliance with the legislation. The accepted legal standards for potable water for human consumption in Brazil are established by Board Resolution - RDC 274/2005 of the National Health Surveillance Agency (ANVISA) - which regulates mineral water and Ordinance 518/2004 of the Ministry of Health which defines minimum standards for drinking water. Water samples in $20 \mathrm{~L}$ bottles of three different trademarks acquired in six commercial localities were analyzed monthly. 
Physicochemical parameters were compared with those predicted in the legislation for turbidity, $\mathrm{pH}$, nitrate, iron, manganese, aluminum, fluoride, and microbiological indicators such as total coliform and Escherichia coli. The results indicated that the $\mathrm{pH}$ was often below the limit allowed by public supply. Deviation from the recommended concentration was most exceeded for aluminum, presenting values significantly high to the standards allowed in two trademarks. Fluoride concentrations were close to zero, although the legislation recommends values between $1 \mathrm{mg} / \mathrm{L}$ and $2 \mathrm{mg} / \mathrm{L}$. The microbiological parameters in some localities and all trademarks registered total coliform, but Escherichia coli were present in only one sample. The mineral water consumed has been considered a safe product compared to other sources, but this study showed that the mineral water marketed in Macapá was often not in accordance with the law. Special attention is recommended for monitoring water quality in $20 \mathrm{~L}$ bottles.

Keywords: Mineral water, RDC 274/2005, physical-chemical analysis, total coliform, public health.

\section{INTRODUÇÃO}

A preocupação com a qualidade da água, decorrente da progressiva poluição hídrica, é um dos motivos que levam grande parte da população mundial ao consumo de água proveniente de fontes minerais (Leclerc e Moreau, 2002). A percepção de que a ingestão desta água remete a um estilo de vida saudável tem aumentado seu consumo no Brasil e no mundo (Mavridou, 1992).

Na última década sua produção duplicou nos EUA e na Suíça (Wynn et al., 2009). O Brasil é o sexto maior produtor do mundo, com aproximadamente 3,5 bilhões de litros registrados no ano de 2000. A região Sudeste é responsável pela maior produção (53\%), sendo 36,9\% só no estado de São Paulo. O Nordeste é o segundo, respondendo por 25,1\% (Resende e Prado, 2008). Isso se deve principalmente às propriedades terapêuticas e medicinais atribuídas ao produto. O conceito de pureza associada é, também, responsável por seu aumento de consumo, mas não se tem certeza sobre a superioridade desta em relação à água de abastecimento público (Pontara et al., 2011).

A RDC/274 (ANVISA, 2005) caracteriza as águas minerais como obtidas diretamente de fontes naturais ou artificialmente captadas de origem subterrânea. São determinadas pelo conteúdo definido e constante de sais minerais e presença de oligoelementos. O elemento predominante na sua composição varia com as rochas e terrenos pelos quais percorre enquanto infiltra-se no solo, podendo apresentar alterações devido às condições hidrogeológicas, hidroclimáticas e a biota (Resende e Prado, 2008).

Independente da fonte (superficial ou subterrânea) a água pode servir de veículo para vários agentes biológicos e químicos sendo necessário observar os fatores que podem interferir negativamente na sua qualidade (Di Bernardo, 1993).

Dentre as substâncias encontradas na água, o composto nitrogenado em seus diferentes estados de oxidação (nitrogênio amoniacal, nitrito e nitrato) pode apresentar riscos à saúde humana (Alaburda e Nishihara, 1998). A presença do nitrogênio na água pode ser de origem natural, como matéria orgânica e inorgânica e chuvas; e antrópica, como esgotos domésticos e industriais. $\mathrm{O}$ nitrato, um dos mais encontrados em águas naturais, apresenta-se em baixos teores nas águas superficiais, podendo alcançar altas concentrações em águas profundas, como nas fontes minerais, por ser altamente lixiviante nos solos, contaminando corpos d'água e aquíferos subterrâneos (Alaburda e Nishihara, 1998).

$\mathrm{Na}$ RDC/274 (ANVISA, 2005) o nitrato deve apresentar valor máximo permissível (VMP) de $50 \mathrm{mg} / \mathrm{L}$ em águas minerais naturais. Seu consumo está diretamente relacionado com a caracterização de dois fatores adversos à saúde, como indução à metemoglobinemia e a formação potencial de nitrosaminas e nitrosamidas carcinogênicas. 
O íon fluoreto, encontrado em águas minerais, deve apresentar concentrações abaixo de $1 \mathrm{mg} / \mathrm{L}$, conforme a legislação. Sua ingestão acima de $2 \mathrm{mg} / \mathrm{L}$ é considerada inadequada para lactentes e crianças com até 7 anos de idade, podendo acarretar o surgimento de fluorose dental e óssea. Por outro lado, a presença de fluoreto em água de consumo, em níveis recomendados, é a forma mais eficiente e coletiva para a prevenção de cáries (Brandão e Valsecki Júnior, 1998; Bulcão e Rebelo, 2009).

Metais também podem comprometer a qualidade da água. Silva (1997) afirma que a intoxicação por metais se desenvolve lentamente e muitas vezes só pode ser identificada após anos ou decênios, e sua presença reduz a capacidade autodepurativa da água devido a ação tóxica sobre os microorganismos que realizam esse processo.

Os metais presentes na água, quando ingeridos, são absorvidos pelo organismo humano pelo trato gastrintestinal e a absorção pode ser afetada pelo $\mathrm{pH}$ da água, pelas taxas de movimentação no trato digestivo e pela presença de outros compostos (Freitas et al., 2001). Sua ingestão também pode causar distúrbios gastrointestinais e até disfunção mental com degeneração do sistema nervoso central. Dentre os mecanismos de sua toxicidade estão incluídas as interações com sistemas enzimáticos, interações com membranas celulares e efeitos específicos sobre certos órgãos e sobre o metabolismo celular em geral (Morgano et al., 2002).

Em relação aos microrganismos presentes na água mineral, Pontara et al. (2011) afirmam que a percepção de que a água mineral é segura e isenta de impurezas deve ser repensada, sendo necessário avaliar critérios de monitoramento e análise microbiológica.

A população em geral considera a água mineral segura, mas não existem estudos que comprovem esta hipótese para a maioria das cidades brasileiras. Pesquisas realizadas em etapas curtas podem ser inadequadas para avaliar fontes de água (Alves et al., 2002; Morgano et al., 2002; Pontara et al., 2011). Com o objetivo de estudar parâmetros físico-químicos e microbiológicos da água mineral comercializada na cidade de Macapá, avaliou-se sua conformidade em relação à legislação vigente. A partir desta perspectiva foi definida uma metodologia de monitoramento mensal da qualidade da água num horizonte temporal de dois anos consecutivos.

\section{MATERIAL E MÉTODOS}

Foram analisadas amostras de três marcas de água mineral em garrafões de $20 \mathrm{~L}$, identificadas como A, B e C, adquiridas em diferentes estabelecimentos comerciais escolhidos aleatoriamente na área urbana. Como o objetivo da pesquisa foi apenas quantificar e comparar os parâmetros físico-químicos e microbiológicos com os previstos na legislação vigente, julgamos desnecessário informar as marcas comerciais referenciadas acima.

Os vasilhames originais estavam lacrados, sem possibilidade de contaminação externa no período entre a aquisição e as análises. O período de estudo ocorreu entre julho de 2009 a julho de 2011.

Os parâmetros físico-químicos e microbiológicos foram escolhidos como variáveis explicativas, especialmente a conformidade dos mesmos à RDC 274/2005 (ANVISA, 2005) e Portaria 518/2004 (Brasil, 2004). No total, foram analisadas 150 amostras em duplicatas.

O parâmetro turbidez foi determinado pelo método turbidimétrico (turbidímetro portátil HACH 2100P). É um indicador da transparência física da água e não necessariamente um parâmetro de potabilidade.

Para a determinação de metais, as amostras foram acondicionadas em garrafas plásticas, lavadas em solução de ácido clorídrico 1:9 para a preservação de suas características 
CUNHA, H. F. A.; LIMA, D. C. I.; BRITO, P. N. de F.; CUNHA, A. C. da; SILVEIRA JUNIOR, A. M. da; BRITO, D. C. Qualidade físico-química e microbiológica de água mineral e padrões da legislação. Ambi-Agua, Taubaté, v. 7, n. 3, p. 155-165, 2012. (http://dx.doi.org/10.4136/ambi-agua.908)

químicas. As concentrações foram determinadas pelos métodos espectrofotométricos: Ferro pelo método FerroVer ${ }^{\circledR}$, Manganês pelo método PAN e Alumínio pelo método AluVer ${ }^{\circledR}$.

$\mathrm{O} \mathrm{pH}$ foi analisado pelo método potenciométrico com pH-âmetro Orion. As concentrações das frações de nitrogênio foram determinadas pelos métodos espectrofotométricos: fração nitrato $\left(\mathrm{NO}_{3}{ }^{-}\right)$pelo método NitraVer ${ }^{\circledR}$. A concentração de fluoreto foi determinada pelo método SPADNS ${ }^{\circledR}$, com uso do espectrofotômetro (APHA et al., 2003).

Para os parâmetros microbiológicos, a coleta foi realizada em recipientes assépticos e as análises identificaram a presença ou não de bactérias do grupo de coliformes (coliformes totais) e de E. coli. Ambos foram quantificados pelo método do substrato cromogênico com reagente COLILERT/IDEXX. Posteriormente foram acondicionadas em bolsas estéreis (ThioBag) no interior da qual foi individualmente adicionado um flaconete de substrato para interagir com os microrganismos em análise. Após a diluição do substrato, a amostra foi transferida para uma cartela estéril e depois lacrada em uma seladora Quanti-Tray Sealer. As cartelas foram inseridas em estufa a $35 \pm 0,5^{\circ} \mathrm{C}$ durante $24 \mathrm{~h}$. As leituras foram realizadas com auxílio de câmera escura sob luz ultravioleta (Alves et al., 2002).

Análise de Variância (ANOVA - Dupla Entrada) (Hand, 2008; Magnusson e Mourão, 2009; Wilcox, 2009) foi aplicada para testar significativas diferenças físico-químicas e microbiológicas entre as marcas (3 marcas em duplicatas) e ao longo do eixo temporal (25 meses).

\section{RESULTADOS}

Com base nas informações obtidas dos parâmetros da qualidade da água mineral a Tabela 1 mostra os valores médios e os respectivos intervalos de confiança em torno dessas médias $(95 \%)$.

Os valores médios da turbidez não apresentaram variação significativa entre as seis amostras $\left(F_{[5,24]}=1,74\right.$ e $\left.p=0,13\right)$ nem ao longo do período $\left(F_{[5,24]}=1,01\right.$ e $\left.p=0,46\right)$.

Em relação aos valores médios de $\mathrm{pH}$ observou-se variações significativas, tanto entre períodos $\left(F_{[5,24]}=9,17\right.$ e $\left.p=9,07 \mathrm{E}^{-12}\right)$ quanto entre as marcas $\left(F_{[5,24]}=2,03\right.$ e $\left.p=0,031\right)$, conforme indicado na Figura 1a. Portanto, a variação global é significativa e está em desacordo com um único valor constante normalmente encontrado em rótulos de vasilhames em todas as marcas e por períodos longos, normalmente anuais.

Tabela 1. Média e intervalos de confiança dos parâmetros da qualidade da água.

\begin{tabular}{|c|c|c|c|c|c|c|}
\hline \multirow[t]{2}{*}{ Parâmetros } & \multicolumn{6}{|c|}{$\begin{array}{l}\text { Valores de parâmetros físico-químicos e microbiológicos da água mineral } \\
\qquad(\text { Média } \pm 1,96 * \mathrm{dp}=95 \%)\end{array}$} \\
\hline & Marca A1 & Marca A2 & Marca B1 & Marca B2 & Marca C1 & Marca C2 \\
\hline Turbidez (UT) & $0,13 \pm 0,08$ & $0,13 \pm 0,09$ & $0,14 \pm 0,12$ & $0,15 \pm 0,13$ & $0,21 \pm 0,21$ & $0,30 \pm 1,20$ \\
\hline $\mathrm{pH}$ & $4,47 \pm 0,86$ & $4,43 \pm 0,92$ & $4,04 \pm 0,71$ & $4,01 \pm 0,72$ & $4,82 \pm 1,14$ & $4,82 \pm 1,14$ \\
\hline Nitrato (mg/L) & $2,13 \pm 1,03$ & $2,27 \pm 1,21$ & $29,65 \pm 10,27$ & $29,03 \pm 11,77$ & $1,86 \pm 1,06$ & $1,90 \pm 1,04$ \\
\hline Fluoreto (mg/L) & $0,05 \pm 0,11$ & $0,07 \pm 0,14$ & $0,06 \pm 0,13$ & $0,05 \pm 0,11$ & $0,06 \pm 0,17$ & $0,06 \pm 0,12$ \\
\hline Ferro $(\mathrm{mg} / \mathrm{L})$ & $0,02 \pm 0,02$ & $0,02 \pm 0,03$ & $0,02 \pm 0,03$ & $0,02 \pm 0,02$ & $0,03 \pm 0,03$ & $0,02 \pm 0,04$ \\
\hline Manganês (mg/L) & $0,00 \pm 0,01$ & $0,00 \pm 0,01$ & $0,01 \pm 0,01$ & $0,01 \pm 0,01$ & $0,01 \pm 0,01$ & $0,01 \pm 0,03$ \\
\hline Alumínio (mg/L) & $0,06 \pm 0,03$ & $0,06 \pm 0,05$ & $0,47 \pm 0,29$ & $0,47 \pm 0,25$ & $0,03 \pm 0,03$ & $0,03 \pm 0,04$ \\
\hline \multicolumn{7}{|l|}{ Coliformes Totais } \\
\hline (NMP/100 mL) & $0,08 \pm 0,46$ & $1,54 \pm 13,68$ & $0,08 \pm 0,80$ & $0,30 \pm 2,94$ & $0,81 \pm 6,77$ & $0,41 \pm 2,08$ \\
\hline (E. coli $(\mathrm{NMP})$ & $0,00 \pm 0,00$ & $0,00 \pm 0,00$ & $0,00 \pm 0,00$ & $0,00 \pm 0,00$ & $0,00 \pm 0,00$ & $0,03 \pm 0,26$ \\
\hline
\end{tabular}


Quanto ao íon nitrato todas as marcas apresentaram conformidade com os níveis de concentração exigido pela legislação. Contudo, a marca B (1 e 2) apresentou valores próximos do máximo permitido em duas amostras coletadas (Figura 1b). Foi possível observar na Figura $1 b$ que houve variação significativa entre as médias de concentração do íon nitrato entre as médias das amostras $\left(F_{[525]}=2,14, p=0,0038\right)$ e ao longo do tempo $\left(F_{[5,25]}=548,57\right.$, $p<0,05)$.

As médias das concentrações de ferro não apresentaram variação significativa no eixo temporal $\left(F_{[5,24]}=2,28\right.$ e $\left.p=0,051\right)$, apesar desta se apresentar muito próxima do limite da significância. Por outro lado, foram observadas diferenças significativas entre as médias das três marcas $\left(F_{[5,24]}=3,05\right.$ e $\left.p=3,16 \mathrm{E}^{-05}\right)$.

As médias das concentrações de manganês indicaram variações significativas, tanto entre as marcas $\left(F_{[5,24]}=3,09\right.$ e $\left.p=2,65 \mathrm{E}^{-05}\right)$ quanto no eixo temporal $\left(F_{[5,24]}=10,44\right.$ e $\left.p=2,44 \mathrm{E}^{-08}\right)$.

O flúor apresentou níveis de concentração médios que variaram ao longo do período amostral de 0,00 a 0,19 $\mathrm{mgF}^{-} / \mathrm{L}$ (Figura 1c). Estes níveis estão abaixo do estipulado pela legislação, impedindo que a água sirva como prevenção à cárie, principal função do fluoreto em águas de consumo humano. Assim, estes resultados não indicaram significativa variação entre as médias amostrais ao longo do eixo temporal $\left(F_{[5,24]}=0,378, p=0,86\right)$. Contudo, acusou diferenças significativas entre as marcas $\left(F_{[5,24]}=2.877, p=0,0132\right)$. Neste caso, ressalta-se que as análises para detecção de fluoreto devam ser realizadas com frequência anual ou bimestral na indústria.

Destaca-se que somente a marca C (1 e 2) continha informação em seu rótulo sobre as concentrações de fluoreto, indicando nível igual a $0,02 \mathrm{mgF}^{-} / \mathrm{L}$. Este valor é menor que a metade dos valores médios obtidos nas análises das amostras $\left(0,057 \mathrm{mgF}^{-} / \mathrm{L}\right)$. As demais marcas não apresentaram qualquer informação.

Quanto à concentração média de alumínio houve variações significativas, tanto entre as marcas $\left(F_{[5,24]}=2,88\right.$ e $\left.p=7,83 \mathrm{E}^{-05}\right)$ quanto no período $\left(F_{[5,24]}=240,95\right.$ e $\left.p=8,13 \mathrm{E}^{-61}\right)$. A marca B (1 e 2) apresentou não conformidade com a legislação (Figura 1d), sendo que os elevados valores médios apresentados por esta marca podem incorrer em risco à saúde pública, com média geral das amostras em torno de $0,18 \mathrm{mg} / \mathrm{L}$, e próximo do limite máximo permitido de $0,20 \mathrm{mg} / \mathrm{L}$ pela Portaria MS 518/2005.

Em relação ao parâmetro microbiológico coliforme total, verificou-se que as médias das concentrações não apresentaram diferenças significativas no período $\left(F_{[5,24]}=0,73\right.$ e $p=$ $0,60)$ ou entre as marcas $\left(F_{[5,24]}=1,0\right.$ e $\left.p=0,55\right)$. Contudo, as concentração apresentaram frequentemente não-conformidade microbiológica para todas as marcas no período de análise. Além disso, valores não-zero ocorreram apenas na marca $\mathrm{A} 1$, três vezes no total de vinte e cinco amostras. $\mathrm{O}$ mesmo ocorreu com a marca $\mathrm{A} 2$, com duas ocorrências em vinte e cinco amostras. Nas marcas B1 e B2 foi registrada uma única ocorrência no período e no total de vinte e cinco amostras. Para a marca $\mathrm{C} 1$ foram registradas quatro ocorrências e em $\mathrm{C} 2$ cinco ocorrências de não-conformidade (Figura 1e).

Em relação ao parâmetro microbiológico fecal E. coli foi registrada presença em uma única amostra em outubro de 2010, na marca C2. Portanto, em conjunto, os resultados não apresentaram variações significativas nem no período $\left(F_{[5,24]}=1,00\right.$ e $\left.p=0,42\right)$ nem entre as marcas $\left(F_{[5,24]}=1,0\right.$ e p $\left.=0,47\right)$. 
CUNHA, H. F. A.; LIMA, D. C. I.; BRITO, P. N. de F.; CUNHA, A. C. da; SILVEIRA JUNIOR, A. M. da; BRITO, D. C. Qualidade físico-química e microbiológica de água mineral e padrões da legislação. Ambi-Agua, Taubaté, v. 7, n. 3, p. 155-165, 2012. (http://dx.doi.org/10.4136/ambi-agua.908)
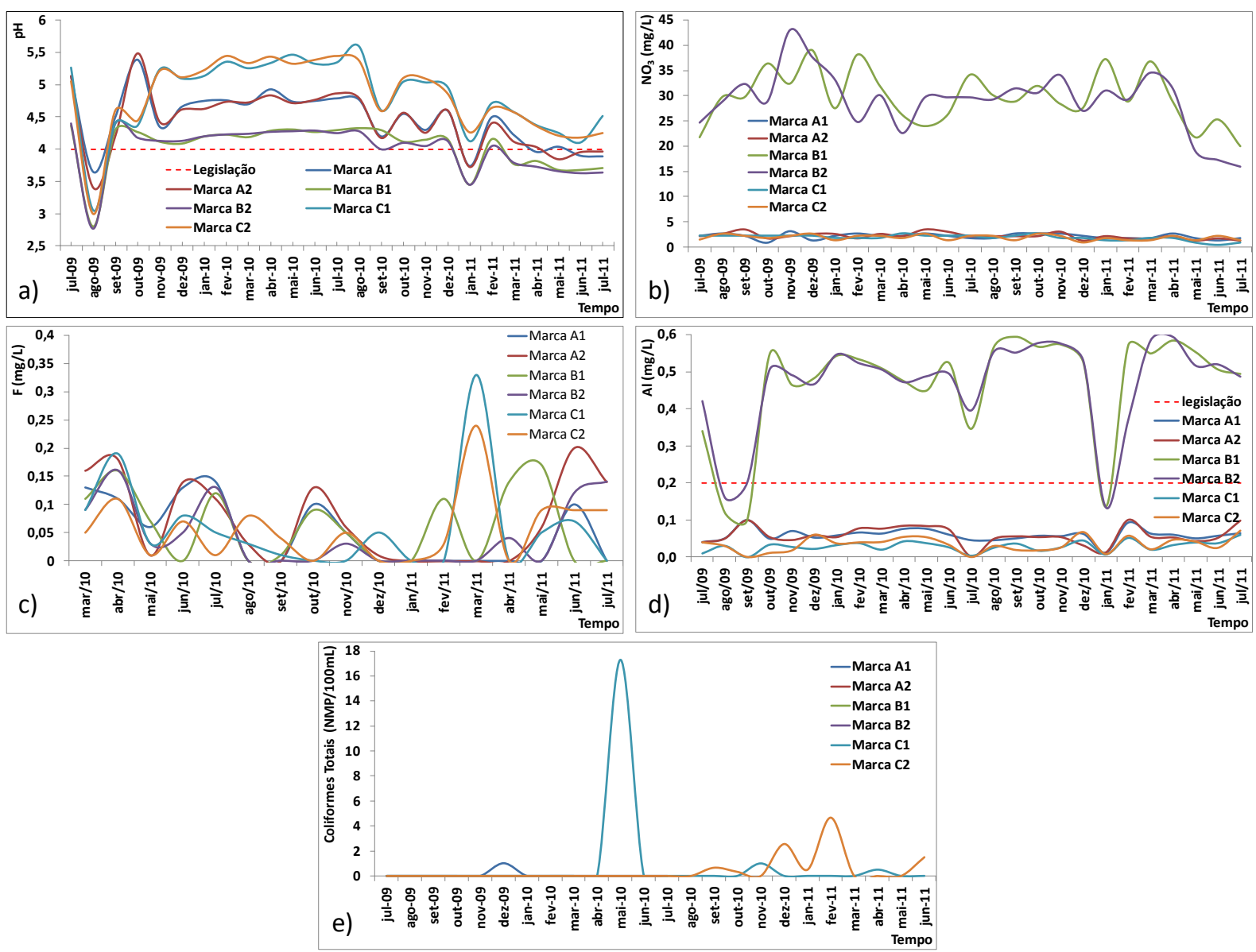

Figura 1. Parâmetros físico-quimicos e microbiológicos da qualidade da água mineral em vasilhames de 20 L. As linhas pontilhadas em vermelho indicam padrões na legislação para as concentrações das amostras: a) variação de $\mathrm{pH}$; b) variação da concentração de $\mathrm{NO}_{3}$; c) variação da concentração de $\mathrm{F}$; d) variação da concentração de $\mathrm{Al}$ e e) variação da concentração de coliformes totais.

\section{DISCUSSÃO}

As amostras de água mineral apresentaram pH médios entre 4,13 e 4,82, sugerindo que as águas não são significativamente mineralizadas. De acordo com Felski et al. (2008) águas ácidas, por serem menos mineralizadas e mais leves, são mais aceitáveis para o consumo do que as águas alcalinas, o que explica o seu elevado consumo. Acidez mais elevada pode advir de fonte natural, sendo mais propícia para as águas minerais, ou pode ocorrer pela dissolução de rochas, por processos de absorção de gases da atmosfera e processos fotossintetizantes.

Apesar de a acidez ser desejável há limites legais estipulados para este parâmetro, entre 4,0 e 9,0. Embora algumas amostras em determinados períodos se apresentaram pouco abaixo de 4,0 houve variações significativas entre as marcas e ao longo do tempo. Portanto, apesar das amostras se apresentarem dentro dos padrões legais, se encontraram frequentemente próximas ou abaixo dos limites (Figura 1a). Tais variações da acidez das águas levam muitos estudiosos a considerarem como característica duvidosa de sua qualidade (ANVISA, 2005).

Segundo Brandão e Valsecki Jr. (1998) geralmente a qualidade das águas subterrâneas tende a variar ao longo do tempo. Mas a legislação só exige análises físico-químicas de controle nas indústrias anualmente. Contudo, as datas das análises não estavam impressas nos rótulos dos garrafões de duas marcas usadas neste estudo.

Os níveis de concentração de nitrato observados foram preocupantes, apesar de ainda estarem em conformidade com a RDC 274/2005 (ANVISA, 2005), a qual estabelece o Valor 
Máximo Permitido (VPM) de $50 \mathrm{mg} / \mathrm{L}$. Mas, este valor quando calculado como fração de nitrogênio na forma de nitrato, converte-se para 11,3 mg/L(N-NO${ }_{3}{ }^{-}$(Nóbrega et al., 2008). Neste caso, está em não-conformidade com a Portaria $n^{\circ} 518$ (Brasil, 2004) que estabelece o limite máximo de $10 \mathrm{mg} / \mathrm{L}\left(\mathrm{N}_{-} \mathrm{NO}_{3}{ }^{-}\right)$para águas de abastecimento público. Em todo caso, esta concentração pode ser nociva à saúde pela indução de doenças como a metemoglobinemia ou doença do bebê azul.

É importante comentar que as fontes subterrâneas profundas tornam-se um ótimo ambiente para a presença natural deste íon, mas que não excluem o seu efeito adverso à saúde, sobretudo nas crianças que possuem em seu sistema digestivo condições ótimas para a redução bacteriológica do nitrato a nitrito, principal causa da metemoglobinemia (Fernícula e Azevedo, 1981).

Outro aspecto relevante é quanto a importância do íon $\mathrm{NO}_{3}$ para compará-los com valores de concentração ao longo do tempo e em relação à exposição de seus valores nos rótulos comerciais, normalmente constantes. No presente caso, foi observada uma significativa diferença entre as médias das concentrações de nitrato (Figura 1b), cujos valores potencialmente podem alcançar níveis além da margem aceitável de concentração.

A afirmação acima é relevante porque se estima que as análises de controle representadas nos rótulos comerciais de água mineral foram realizadas, em média, há pelo menos um ano antes da pesquisa, ocorrendo o mesmo problema para o parâmetro $\mathrm{pH}$, onde os rótulos não acusaram nenhuma alteração de valor nas concentrações hidrogeniônicas informadas e ao longo do período. Nestes termos, o valor único e constante impressos nos rótulos das embalagens tende a mascarar a variação real observada se o monitoramento fosse mensal (Figura 1a).

O mesmo pode ocorrer com o flúor. Brandão e Valsecki Júnior (1998) revelaram que dezesseis amostras contendo flúor, do total de trinta e duas analisadas, apresentaram valores abaixo do permitido pela legislação, sendo detectados valores da ordem de 0,02 mgF/L. Dentre as amostras observadas pelos referidos autores somente oito apresentavam no seu rótulo a concentração de fluoreto. Isto contraria a legislação, vez que as empresas de água mineral são obrigadas a informar o consumidor sobre a qualidade físico-química do produto. $\mathrm{Na}$ presente pesquisa foram observados valores intermediários de flúor, sendo que apenas uma marca C (1 e 2) foi detectada informações desta natureza em rótulo (Figura 1c).

A importância do ferro na região amazônica apresenta caráter mais estético do que de potabilidade. As fontes minerais desta região podem apresentar valores que facilmente excedem os limites da legislação sem, contudo, representar riscos reais à saúde. Por outro lado, as concentrações de manganês foram identificadas abaixo do limite máximo de 0,500 $\mathrm{mg} / \mathrm{L}$ estabelecido pela legislação, encontrando-se em conformidade com a legislação.

Por outro lado, o parâmetro alumínio apresentou variação significativa entre as concentrações médias amostrais ao longo do tempo e entre as médias das diferentes marcas. A importância da afirmação está no consumo de altas concentrações de alumínio potencialmente associado aos distúrbios que provocam o mal de Alzheimer (Freitas et al., 2001). Portanto, trata-se de uma preocupação com a comercialização e fiscalização da água com alto teor deste metal, pois as informações referentes aos metais ferro, alumínio e manganês não foram registrados nos rótulos das três marcas monitoradas. Isso porque estas informações não são obrigatórias na legislação para proteger o consumidor do uso exagerado de água mineral com altos teores de alumínio, o que é um contra-senso. Nestes casos, sugerimos que os órgãos fiscalizadores estejam alertas quanto ao potencial consumo deste metal frequentemente observado na água mineral analisada nesta pesquisa.

É importante frisar que, amostras de água mineral alteradas, permitem inferir que podem ter ocorrido contaminações durante a fase de captação e processamento do produto (Alves et 
al., 2002) ou mesmo devido aos efeitos sazonais do clima sobre a composição físico-química ou microbiológica (Silva et al., 2002).

Nestes casos, Silva et al. (2002) avaliaram os efeitos sazonais do clima na composição físico-química de amostras de água mineral provenientes de diferentes fontes em São Paulo $(\mathrm{Ba}, \mathrm{Ca}, \mathrm{K}$ e $\mathrm{Mg}$ ). Os referidos autores afirmaram que é possível verificar que a constituição da água mineral pode ser utilizada como "impressão digital" para fins de estudo de rastreabilidade das águas minerais por apresentarem variações temporais não-significativas.

Contudo, as afirmações de Silva et al. (2002) podem ser questionadas porque considerou apenas um período curto de três meses. Talvez este prazo seja insuficiente para detectar as variações amostrais, tais como as observadas no presente estudo. Do ponto de vista analítico, acreditamos que um curto prazo de análise não é suficiente para obter uma variação significativa e manter a hipótese de constância das características químicas ao longo de um período anual para a maioria dos parâmetros físico-químicos e microbiológicos.

Quanto aos aspectos microbiológicos, mesmo que não ocorram registros bacteriológicos em amostras de água mineral (coliformes totais e E. coli), na literatura tem sido considerados outros parâmetros além dos normalmente utilizados para analisar o teor microbiano. Por exemplo, a ausência de coliformes ou $E$. coli não exclui, por exemplo, fungos e filamentosos, independentemente do resultado negativo da análise bacteriológica. Alguns autores afirmam que desconsiderá-los pode representar um problema, em especial para usuários não saudáveis de águas, como pacientes imunocomprometidos (Pontara et al., 2011).

A partir de uma tendência da aplicação da legislação vigente para águas minerais, Alves et al. (2002) afirmam que, após sofrer atualização da Resolução RDC 274 (ANVISA, 2005), houve otimização quanto ao seu espectro microbiológico. Mas ainda é insuficiente para manter o controle de qualidade e está aquém do que exige o padrão da legislação internacional (americana e européia) para a comercialização deste produto (Wynn et al., 2009).

\section{CONCLUSÕES}

No período entre julho de 2009 a junho de 2011 foram determinadas não somente as médias mas as variâncias de cada parâmetro da qualidade da água concernentes às marcas comerciais existentes na cidade de Macapá. Além disso, com base nos poucos estudos da literatura, verificou-se a necessidade de investigações em períodos mais prolongados. Com efeito, foram observadas influências da sazonalidade (entre e inter-ano) onde se constatou significativa variação de alguns parâmetros. Tal efeito corrobora a hipótese de que a rotulagem de valores fixos de qualidade da água não é recomendada.

A água mineral comercializada na cidade de Macapá atendeu apenas parcialmente as especificações previstas em normas de vigilância e saúde, dependendo do período sazonal, pois alguns parâmetros estavam em não-conformidade em relação aos previstos na legislação. Desta forma, podemos resumir da seguinte maneira nossas conclusões:

1. A água comercializada em Macapá frequentemente não atendeu às exigências da legislação, especialmente em relação ao $\mathrm{pH}$, elevado conteúdo de alumínio, frequente presença de coliformes totais em mais de 5\% das amostras analisadas (ou seja 10\% ou mais), não observação das concentrações de flúor no rótulo, e oscilação sazonal das concentrações de nitrato.

2. Os parâmetros microbiológicos regulamentados pela legislação (coliformes totais) são considerados bons ou adequados quando apresentam até três coliformes totais em $100 \mathrm{~mL}$ em $5 \%$ das amostras analisadas no mês e coliformes fecais ausentes (E. coli). Contudo, nas amostras avaliadas, apenas $90 \%$ estavam aptas ao consumo, índice bastante inferior ao recomendado pela legislação. A presença de E. coli em água mineral indica necessidade de melhorar o controle de qualidade do produto. 
3. Observaram-se variações sazonais significativas das amostras de mesma marca e de marcas distintas, com destaque para o metal Alumínio, registradas em níveis acima do permitido pela legislação, comprometendo a qualidade da água. Este parâmetro é um componente neurotóxico, além de indutor ou causador de distúrbios neurológicos. Neste sentido, a legislação atual pareceu inadequada sob vários aspectos, pois o Alumínio não consta como obrigatório no monitoramento e na regulamentação brasileira.

4. O descumprimento da legislação ao se omitir informações corretas nos rótulos, sobre as concentrações dos constituintes da água, impossibilitou comparações entre valores apresentados e para fins de fiscalização ou monitoramento. No processo de rotulagem dos vasilhames de água mineral as informações devem ser adequadamente visíveis ao consumidor e corrigidas com frequência mínima bimestral, para assegurar as variações dos parâmetros no tempo. No entanto, o que se observou nos rótulos foi um valor fixo de sua composição ao longo do tempo ou mesmo entre amostras. Mas este fato foi contestado na presente pesquisa.

5. A significativa variação sazonal da acidez, da concentração de metais e de íons na água mineral, é um fator adicional de risco à saúde humana, em razão de que esta tende a agravar o potencial de certos constituintes que não são previstos na legislação. Por exemplo, ao se excluir os valores máximos da concentração de ferro e alumínio da legislação incorre em potencial prejuízo ao consumidor por este ignorar os riscos associados ao consumo desses metais.

6. Finalmente, a qualidade da água mineral em garrafões de $20 \mathrm{~L}$ apresentou considerável vulnerabilidade físico-química e microbiológica, necessitando ser monitorada em todas as suas etapas produtiva e comercial. Além disso, é necessário inserir na lista de parâmetros de qualidade novos componentes potencialmente perigosos à saúde humana, e que atualmente não são nem sequer exigidos pelos órgãos de fiscalização, a exemplo do metal Alumínio.

\section{AGRADECIMENTOS}

Agradecemos ao CNPq e a Secretaria de Estado da Ciência e Tecnologia (SETEC) pelo auxílio financeiro ao projeto (Convênio CNPq $\mathrm{n}^{\circ}$. 0019/00-07) e concessão de bolsas de iniciação científica (CNPq) e produtividade (CNPq - processo 305657/2009-7).

\section{REFERÊNCIAS}

ALABURDA, J.; NISHIHARA, L. Presença de compostos de nitrogênio em águas de poços. Revista de Saúde Pública, v. 32, n. 2, p. 160-165, 1998. http://dx.doi.org/10.1590/S003489101998000200009

ALVES, N. C.; ODORIZZIA, A. C.; GOULART, F. C. Análise microbiológica de águas minerais e de água potável de abastecimento, Marília, SP. Revista de Saúde Pública, v. 36, n. 6, p. 749-751, 2002. http://dx.doi.org/10.1590/S0034-89102002000700014

AGÊNCIA NACIONAL DE VIGILÂNCIA SANITÁRIA - ANVISA (Brasil). RDC n. 274, de 22 de setembro de 2005. Brasília, 2005. 7 p.

AMERICAN PUBLIC HEALTH ASSOCIATION - APHA; AMERICAN WATER WORKS ASSOCIATION - AWWA; WATER POLLUTION CONTROL FACILITIES - WPCF. Standard methods for the examination of water and wastewater. $20^{\text {th }}$. Edition. Washington, D.C., 2003.

BRANDÃO, I. M. G.; VALSECKI JÚNIOR, A. Análise da concentração de flúor em águas minerais na região de Araraquara, Brasil. Revista Panamericana de Salud Pública, v. 4, n. 4, p. 238-242, 1998. http://dx.doi.org/10.1590/S1020-49891998001000003 
CUNHA, H. F. A.; LIMA, D. C. I.; BRITO, P. N. de F.; CUNHA, A. C. da; SILVEIRA JUNIOR, A. M. da; BRITO, D. C. Qualidade físico-química e microbiológica de água mineral e padrões da legislação. Ambi-Agua, Taubaté, v. 7, n. 3, p. 155-165, 2012. (http://dx.doi.org/10.4136/ambi-agua.908)

BRASIL. Ministério da Saúde. Portaria 518/GM em 25 de Março de 2004. Estabelece os procedimentos e responsabilidades relativos ao controle e vigilância da qualidade da água para consumo humano e seu padrão de potabilidade, e dá outras providências. Brasília, 2004.

BULCÃO, L. N.; REBELO, M. A. B. Evaluation of the fluoride concentration in mineral water and guaraná-based soft drinks in Manaus, Amazonas. Revista Odonto Ciências, v. 24, n. 3, p. 240-243, 2009.

DI BERNARDO, L. Métodos e técnicas de tratamento de água. Rio de Janeiro: ABES, 1993.

FELSKI, G.; ANAISSI, F. J.; QUINÁIA, S. P. Avaliação da qualidade da água consumida pela população do município de Guarapuava, Paraná. Revista Eletrônica Lato Sensu, ano 3, v. 1, p. 1-25, 2008.

FERNÍCULA, N. G. G.; AZEVEDO, F. A. Metemoglobinemia e nitrato nas águas. Revista de Saúde Pública, v. 15, n. 2, p. 242-248, 1981. http://dx.doi.org/10.1590/S003489101981000200009

FREITAS, M. B.; BRILHANTE, O. M.; ALMEIDA, L. M. Importância da análise de água para a saúde pública em duas regiões do Estado do Rio de Janeiro: enfoque para coliformes fecais, nitrato e alumínio. Cadernos de Saúde Pública, v. 17, n. 3, p. 651660, 2001. http://dx.doi.org/10.1590/S0102-311X2001000300019

HAND, D. J. Statistics: a very short intoduction. Oxford: Oxford University Press, 2008.

LECLERC, H.; MOREAU, A. Microbiological safety of natural mineral water. FEMS Microbiology Reviews, v. 26, n. 2, p. 207-222, 2002. http://dx.doi.org/10.1111/j.15746976.2002.tb00611.x

MAGNUSSON, W. E.; MOURÃO, G. M. Basic statistic in ecological studies: linking the questions to the analyses. Oxford: Oxford University Press, 2009.

MAVRIDOU, A. Study of the bacterial flora of a non-carbonated natural mineral water. Journal of Applied Microbiology, v. 73, n. 4, p. 355-361, 1992. http://dx.doi.org/ 10.1111/j.1365-2672.1992.tb04989.x

MORGANO, M. A.; SCHATTI, A. C.; ENRIQUES, H. A.; MANTOVANI, D. M. B. Avaliação físico-química de águas minerais comercializadas na região de Campinas, SP. Ciência e Tecnologia de Alimentos, v. 22, n. 3, p. 329-343, 2002. http://dx.doi.org/ 10.1590/S0101-20612002000300007

NÓBREGA, M. M. S.; ARAÚJO, A. L. C.; SANTOS, J. P. Avaliação das concentrações de nitrato nas águas minerais produzidas na região da grande Natal. Holos, v. 3, p. 4-25, 2008.

PONTARA, A. V.; OLIVEIRA, C. D. D.; BARBOSA, A. H.; SANTOS, R. A.; PIRES, R. H.; MARTINS, C. H G. Microbiological monitoring of mineral water commercialized in Brazil. Brazilian Journal of Microbiology, v. 42, n. 2, p. 554-559, 2011. http://dx.doi.org/10.1590/S1517-83822011000200020

RESENDE, A.; PRADO, C. N. Perfil microbiológico da água mineral comercializada no Distrito Federal. Revista de Saúde e Biologia, v. 3, n. 2, p. 16-22, 2008. 
CUNHA, H. F. A.; LIMA, D. C. I.; BRITO, P. N. de F.; CUNHA, A. C. da; SILVEIRA JUNIOR, A. M. da; BRITO, D. C. Qualidade físico-química e microbiológica de água mineral e padrões da legislação. Ambi-Agua, Taubaté, v. 7, n. 3, p. 155-165, 2012. (http://dx.doi.org/10.4136/ambi-agua.908)

SILVA, F. V.; KAMOGAWA, M. Y.; FERREIRA, M. M. C.; NÓBREGA, J. A.; NOGUEIRA, A. R. A. Discriminação geográfica de águas minerais do Estado de São Paulo através da análise exploratória. Eclética Química, v. 27, n. especial, p. 1-9, 2002. http://dx.doi.org/10.1590/S0100-46702002000200008

SILVA, M. O. S. A. Análises físico-químicas para controle das estações de tratamento de esgoto. São Paulo: CETESB; 1997.

WILCOX, R. R. Basic statistics: understanding conventional methods and modern 23. insights. Oxford: Oxford University Press, 2009.

WYNN, E.; RAETZ, E.; BURCKHARDT, P. The composition of mineral waters sourced from Europe and North America: composition of mineral water optimal for bone. Britsh Journal of Nutrition, v. 101, n. 8, p. 1195-1199, 2009. http://dx.doi.org/ 10.1017/S0007114508061515 